\title{
Semidiurnal switching of stratification in the region of freshwater influence of the Rhine
}

\author{
J. H. Simpson and A. J. Souza \\ School of Ocean Sciences, University College North Wales, Gwynedd, Wales, United Kingdom
}

\begin{abstract}
Observations in the Rhine region of freshwater influence (ROFI) system in the North Sea show evidence of large semidiurnal oscillations in stability, superimposed on a mean stratification, occurring throughout the stratified region at times of reduced mixing. The amplitude of this semidiurnal variation is of the same order as the mean stability and frequently results in conditions being mixed or nearly mixed once per tide. It is deduced that this semidiurnal variation results primarily from cross-shore tidal straining which interacts with the density gradient to induce stratification. This conceptual picture of the contributing processes has been tested in a one-dimensional point model forced by the observed slopes and the local density gradients. The model exhibits the same qualitative behavior as the observations, produces oscillations in stratification of the amplitude observed, and confirms the critical role of cross-shore tidal straining. The large cross-shore shear under stratified conditions is identified with the changes in ellipse configuration which are observed between mixed and stratified conditions. The occurrence of semidiurnal variations in stability in the Rhine ROFI is thus inferred to be a consequence of the development of mean stability whenever the horizontal density gradients relax in conditions of low stirring.
\end{abstract}

\section{Introduction}

The discharge of an average of $2200 \mathrm{~m}^{3} \mathrm{~s}^{-1}$ of freshwater into the North Sea by the Rhine represents a major source of buoyancy which has important implication for water column structure and dynamics over a large area of the eastern North Sea [de Ruijter et al., 1992; van der Giessen et al., 1990]. In a previous article [Simpson et al., 1993] we have drawn attention to the suite of processes operating in the Rhine Region of freshwater influence (ROFI) on the basis of a series of mooring and survey observations made by a consortium of European scientists in October 1990 as part of the European Community (EC) funded MAST PROFILE project. In this paper we make use of further observations to elucidate the way in which the various processes involved interact to explain some of the complexity in the observed pattern of variability in structure and, in particular, the occurrence of marked semidiurnal fluctuations in stratification.

The basic competition between the stratifying effect of the buoyancy input and the mixing influence of stirring by the tidal flow, winds, and waves leads to an alternation between periods of strong stratification and complete vertical mixing in the Rhine ROFI in much the same way as has been observed elsewhere [e.g., Sharples and Simpson, 1995]. The periodic variation in the intensity of tidal stirring tends to impose a fortnightly cycle on the system, with stratification breaking down at or soon after spring tides. At the same time, variations in wind and wave conditions [Munchow and Garvine, 1993] as well as fluctuations in river discharge introduce more random components of variability. The

Copyright 1995 by the American Geophysical Union.

Paper number $95 \mathrm{JC} 00067$. 0148-0227/95/95JC-00067\$05.00 competition between stabilizing and stirring forces is well visualized in the laboratory experiments of Linden and Simpson [1988], with the important addition, in the real world, of the effects of the Earth's rotation acting to limit the spreading of the density current which gets deflected parallel to the coast, forming a baroclinic contribution to the north flowing current along the Dutch coast.

A further complication apparent in the observed time history of stratification in the 1990 observations was that, even during "stratified" periods, the structure was observed to oscillate with a semidiurnal frequency between a highly stable structure and conditions of near or full vertical mixing. It was recognized that these oscillations, like those observed in Liverpool Bay ROFI, were at least partly attributable to the process of tidal straining [Simpson et al., 1990]. There was, however, also the possibility that the proximity of the moorings to the Rhine source ( $20 \mathrm{~km}$ away) could have contributed additional semidiurnal variability due to the tidal pulsing of discharge from the Rhine. The observations described here clarify the role of straining and allow some conclusions about the origin of the important component of shear in the tidal flow.

\section{Observational Techniques}

The new data were obtained in an extensive observational campaign which was carried out in the Rhine ROFI from September 2-17, 1992, by the research vessel RRS Challenger. An array of five moorings, in the form of a $13 \mathrm{~km}$ square around a central position, was deployed in the ROFI regime with the square center some $35 \mathrm{~km}$ downstream from the Rhine source and $16 \mathrm{~km}$ from the coast (Figure 1a). The array was designed to determine the water column structure and flow and to measure the horizontal density gradients which provide a key driving force. Each mooring was equipped with 

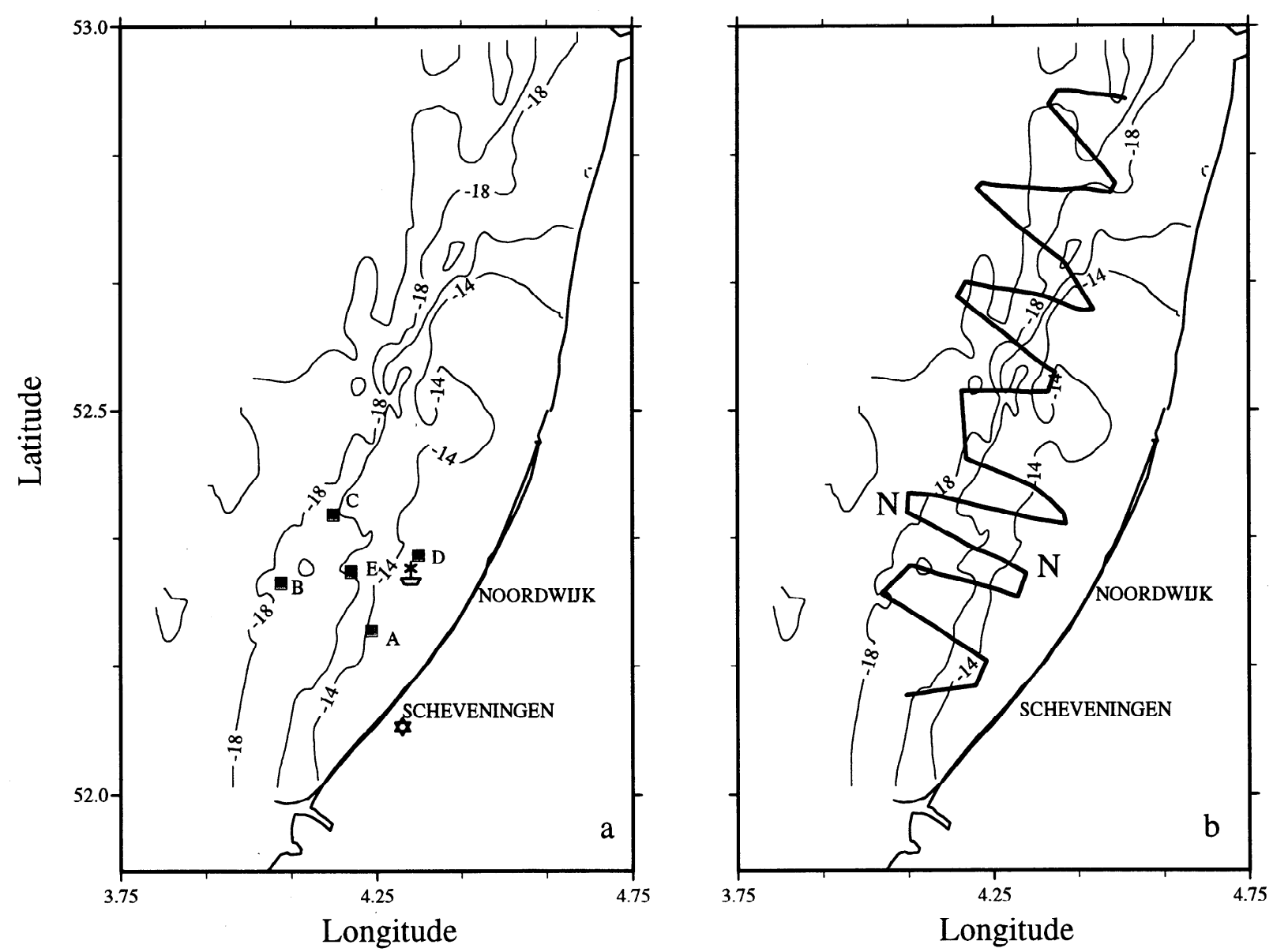

Figure 1. Rhine region of freshwater influence study area showing (a) bathymetry in meters, with mooring positions (squares) and Noordwijk Tower and (b) SEAROVER tracks for survey in the period J.D. 254, 2140 UT, to J.D. 256, 1833 UT.

four Aanderaa current meters (located at depths of 1, 10, 13, and $16 \mathrm{~m}$ ) taking measurements of instantaneous current direction and average speed at intervals of $10 \mathrm{~min}$; all instruments had sensors for temperature and salinity. To ensure accuracy of the salinity time series from the moorings, all instruments were calibrated alongside the ship's conductivity-temperature-depth (CTD) profiler both before and after deployment. The conventional current meters were supplemented by the use of bottom-mounted 1-MHz acoustic Doppler current profilers (ADCPs) to give greater vertical resolution. In order to complement the time series observations and provide a spatial context, we also undertook CTD surveys using the SEAROVER undulator which provides rapid sampling of temperature, salinity, fluorescence, and optical beam transmittance from the surface to within $3 \mathrm{~m}$ of the seabed with a horizontal resolution of about $300 \mathrm{~m}$ at middepth (600 $\mathrm{m}$ at the surface and bottom).

\section{Results}

Times Series

The evolution of stratification $\Delta \sigma_{t}$ at two of the mooring positions (mean depth of $20 \mathrm{~m}$ ) over the study period is illustrated in Figure 2, together with the estimates of tidal stirring, based on the observed tidal velocity and wind stirring derived from wind observations at the Noordwijk tower (Figure 1a), calculated using efficiencies from Simpson and Bowers [1981]. Strong bursts of wind stirring with cncrgy inputs of up to $0.2 \mathrm{~mW} \mathrm{~m}^{-3}$ are seen to dominate at times over the tidal contribution which increases from a low level around neap tides, near the start of the record, to a peak value of $0.1 \mathrm{~mW} \mathrm{~m}^{-3}$ on day 257 . The influence of the combined stirring power inputs is reflected in the mean level of the stratification (Figure 2c): low stratification at the start of density record follows a bout of strong wind mixing, after which lower winds and neap tides allows the development of strong stratification at both moorings with values of the mean bottom to surface density difference $\Delta \sigma_{t} \sim 2 \mathrm{~kg} \mathrm{~m}^{-3}$ on days 254-255. Immediately following this, the combination of an episode of strong wind stirring and spring tides induces an almost complete vertical mixing of the water column.

Superimposed on these changes in the average level of stratification is a very prominent semidiurnal variation (Figure $2 \mathrm{~d}$ ), the amplitude of which is large in relation to the daily mean so that, at the time of minimum stratification, the system approaches complete homogeneity. This semidiurnal signal is apparent at both moorings and shows similar phase and amplitude in both cases.

\section{The Spatial Surveys}

In this first application of an undulator to the survey of the Rhine ROFI regime we investigated a variety of survey 
strategies to observe the space-time evolution of the TS field. By making repeated crossings of the same section, we have attempted to observe the development and decay of stratification in response to changes in the stirring power inputs. Figure 3 illustrates two near-synoptic salinity sections as the horizontal density gradient relaxes under gravity following a sharp drop in wind mixing from high levels on day 259 (Figure 2) when wind speeds exceeded $15 \mathrm{~m} \mathrm{~s}^{-1}$ and SEAROVER profiling was suspended. In such conditions the water column would have been vertically mixed, with all isolines of salinity and temperature vertical. In the first survey after the storm (Figure 3a) the salinity structure was already developing significant stratification approximately 12 hours after the wind fell below $3 \mathrm{~m} \mathrm{~s}^{-1}$. The $S=32$ isohaline, for example, intersects the surface $6 \mathrm{~km}$ farther offshore than at the bottom. In the next section, 7 hours later (Figure $3 \mathrm{~b}$ ), this separation has increased to $12 \mathrm{~km}$ as the offshore displacement of the surface water and the onshore movement of the bottom waters has proceeded and the water column becomes strongly stratified. After relaxation for a total of 19 hours, which is more than the inertial period of 15.2 hours, the system should be close to the final geostrophically adjusted state in which the density-driven flow has been deflected parallel to the coast and stratification is constrained to a $25-\mathrm{km}$-wide band near the coast.
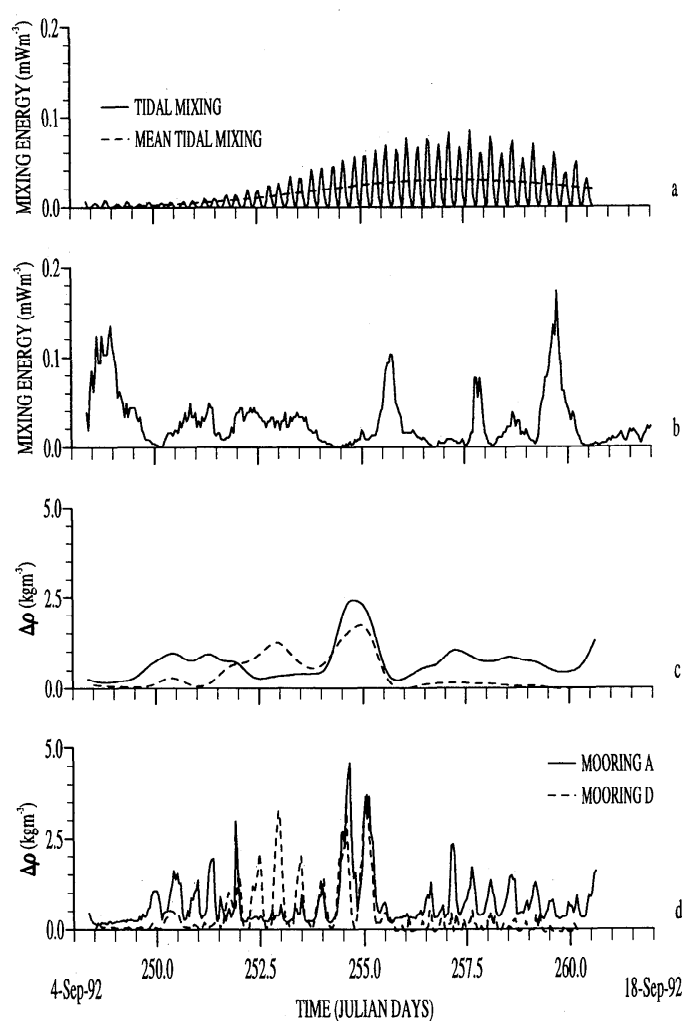

Figure 2. Time serics of stirring power and stratification. (a) Tidal stirring power showing instantaneous value (solid line) and daily mean (dashed line) computed from current meter velocity at mooring A ( $\sim 4 \mathrm{~m}$ above bed). (b) Wind stirring power calculated using wind data from the Noordwijk Tower. Stratification $\Delta \rho$, the density difference between 16 and $1 \mathrm{~m}$ depth, as (c) daily mean and (d) instantaneous values at moorings $\mathrm{A}$ (solid line) and $\mathrm{D}$ (dashed line). Mean water depth is $20 \mathrm{~m}$.
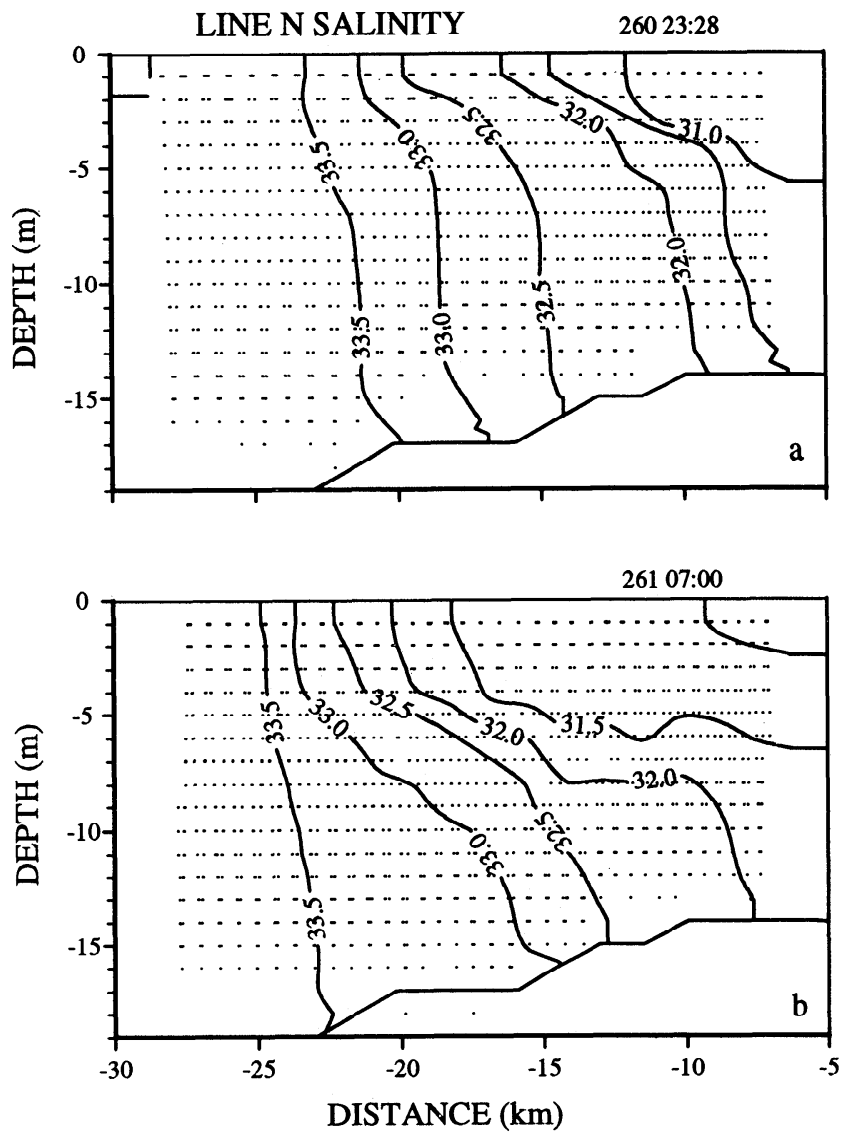

Figure 3. Cross-shore profiles of salinity structure showing the development of stratification following the decrease of wind mixing. Plots are based on measurements from an undulating CTD (SEAROVER) with horizontal resolution of $300 \mathrm{~m}$ on (a) September 16 (J.D. 260) 2228-2359 UT and (b) September 17 (J.D. 261) 0700-0802 UT. The wind speed decreased rapidly from a value of $\sim 15 \mathrm{~m} \mathrm{~s}^{-1}$ at noon on J.D. 259 to $\sim 5 \mathrm{~m} \mathrm{~s}^{-1}$ on J.D. 260.

An example of the reverse process of the breakdown of stratification was observed using a zigzag survey pattern on day 255 when there was a sudden increase in wind stirring from very low levels (see Figure 2). Figure 4a shows a quasi-synoptic map of the density difference between the surface and $12 \mathrm{~m}$, hased on a survey over the period .I.D. 254, 2140 UT, to J.D. 255, 0646 UT. Strong stratification is apparent out to $\sim 20 \mathrm{~km}$ from the coast, beyond which the density was vertically uniform. On the following day, in a repeat survey (Figure $4 \mathrm{~b}$ ), in the presence of winds of $\sim 12 \mathrm{~m}$ $s^{-1}$, we observed vertically homogeneous conditions extending over the entire region except for some slight stratification near the coast. The very rapid decline of stratification in this case may be illustrative of another important feature of the problem.

As well as the effect of the magnitude of the wind stress in contributing to stirring, the direction of the stress may also be relevant to the control of stratification, insofar as offshore and upwelling favorable winds will tend to promote the density current and hence the process of restratification, while onshore and downwelling favorable winds may inhibit the development of stratification. In addition to the dynamical interaction with the density current, onshore winds will 

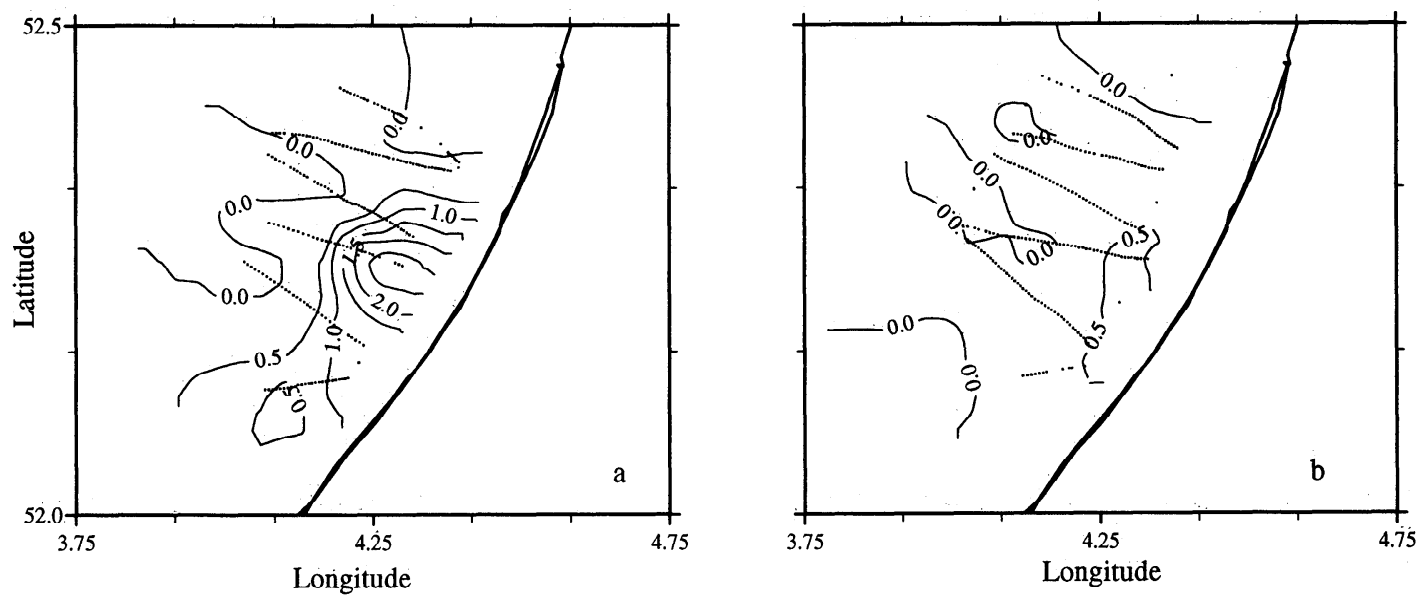

Figure 4. Stratification distribution from SEAROVER survey shown as the density difference $\Delta \rho$ hetween 12 and $1 \mathrm{~m}$ depth (a) on September 11, 1992 (I.D. 255), and (b) on September 12, 1992 (J.D. 256).

be considerably more effective in inducing wave-forced mixing. In the above example of the mixing on day 255 the winds were generally toward the east and thus involved both a strong shoreward component and a downwelling favorable alongshore element which together would tend to promote the rapid breakdown of stratification.

\section{Inferences From the Combined Data Sets}

In the presentation of the SEAROVER survey data above we have had to assume that the evolution of the tempcrature and salinity fields during the survey period can be neglected in constructing quasi-synoptic sections and maps. In many situations this forms a reasonable basis for interpreting the data, especially if we have evidence from fixed sensors that the time development of the structure is slow in relation to the timescale of the survey.

In the present case, however, it is clear from Figure 2 that in the vicinity of the moorings there is a significant evolution of the density field, even on short timescales, due to the marked semidiurnal variation in column structure. If this pattern of variation is a general characteristic of the stratified region, it would seem that time-dependent changes will be interpreted as spatial structures in mapping exercises. In order to test the notion that there is a general semidiurnal oscillation under stratified conditions, we have combined the SEAROVER data with the mooring data for the same period in Figure 5. Surface to bottom density differences observed by the SEAROVER system when inside the ROFI (i.e., within $15 \mathrm{~km}$ of the coast) are plotted as a time series parallel with $\Delta \sigma_{t}$ from mooring $\mathrm{A}$. There is a significant coherence between the envelope of the SEAROVER data and the mooring observations which strongly suggests that the semidiurnal oscillation is a general characteristic of the ROFI. Some differences in the phase of the data from fixed and moving sensors may be expected owing to the change in the phase in tidal processes over the area.

\section{Interpretation in Terms of Tidal Straining}

Semidiurnal variations in water column stability of this kind have been previously identified in other ROFI and estuarine regimes [Bowden and Sharaf el Din, 1966; Uncles et al., 1992; Simpson et al., 1991] and attributed to the influence of tidal straining [Simpson et al., 1990]. The amplitude of semidiurnal variation in the Rhine ROFI is, however, considerably greater in relation to the mean amplitude than in previously observed cases. Reference to the previous observations in 1990 shows similar behavior, as is illustrated, for example, by Simpson et al. [1993, Figure 4], with even larger oscillations of salinity stratification (amplitude $\sim 4$ salinity units) than we observe in the 1992 measurements.

The question then arises as to the role of tidal straining in the present case and whether or not other mechanisms are involved. As a first step in answering these questions, we have plotted in Figure 6 the density stratification alongside the relative tidal displacement (the cross-shore "straining") betweeni surface and bottom water over a 4-day period. This, the more important of the two tidal straining components, has been computed in two different ways. In Figure 6a a predicted shear displacement is obtained from six tidal

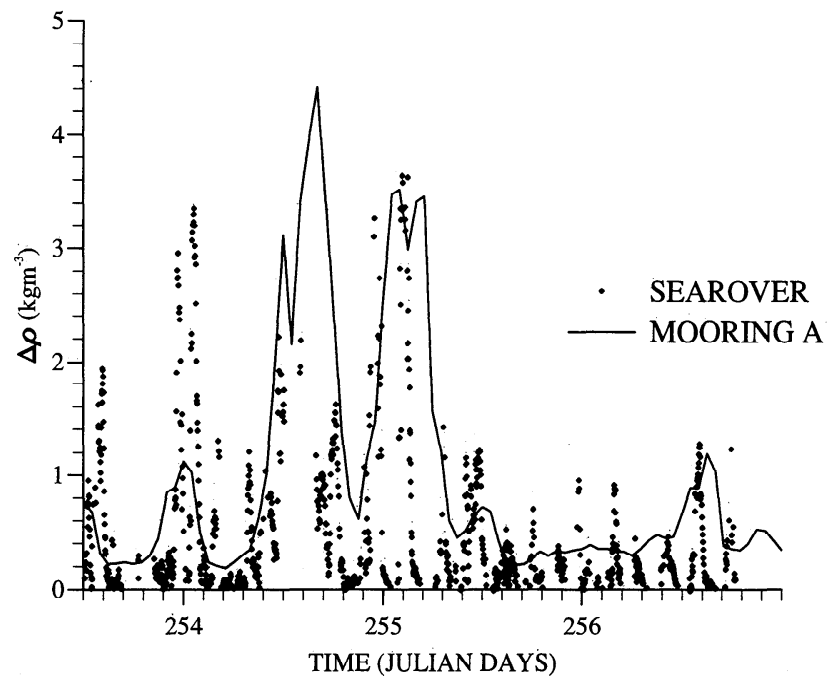

Figure 5. Stratification time series shown as density difference $\Delta \rho$ calculated from SEAROVER data between depths of 12 and $1 \mathrm{~m}$ (dots) and from mooring A data between 17 and $1 \mathrm{~m}$ (solid line). 

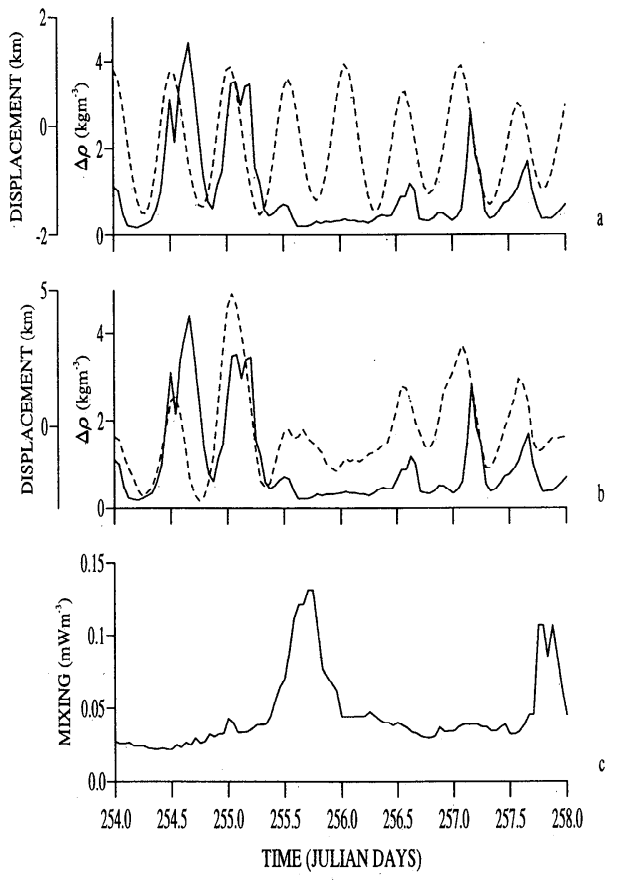

Figure 6. Tịdal straining and periodic stratification. (a) Time series of stratification (solid line) and tidal displacement (dashed line), with displacement calculated using six tidal constituents $\left(\mathrm{M}_{2}, \mathrm{~S}_{2}, \mathrm{~N}_{2}, \mathrm{O}_{1}, \mathrm{~K}_{1}\right.$, and $\left.\mathrm{M}_{4}\right)$ from the top bin ( $3 \mathrm{~m}$ deep) relative to the bottom bin (17 $\mathrm{m}$ deep) from a 1.2-MHz acoustic Doppler current profiler at mooring A. Positive displacement is offshore. (b) Same as Figure 6a, but with displacement calculated from the high-pass-filtered velocities. (c) Estimates of the combined wind and stirring power for the same period.

velocity constituents derived from harmonic analysis over the full duration of the record and shows that the straining signal has an amplitude of $1.5 \mathrm{~km}$ and is somewhat advanced in phase relative to the two large oscillations of stratification $\Delta \rho$ on days $254-255$. This estimate represents the relative displacement corresponding to the case when the vertical coupling between layers remains constant throughout the analysis period.

It differs markedly from the actual relative tidal displacement (Figure 6b) which has been calculated by high pass filtering the ADCP data for the 4-day period. Prior to midday on day 255 there was a strong enhancement of the straining with a relative displacement of $\sim 7 \mathrm{~km}$ between current meters at depths of 4 and $16 \mathrm{~m}$. Following the onset of intense wind mixing on day 255 (Figure 6c), the tidal shear signal was greatly reduced. These changes in the straining signal are clearly reflected in the $\Delta \rho$ variation, suggesting that straining is the primary process driving the semidiurnal stratification cycle.

Neglecting the effects of mixing we may estimate the range of $\Delta \rho$ from straining alone according to

$$
\Delta \rho=\Delta X \frac{\partial \rho}{\partial x}
$$

For a typical cross-shore gradient of $2.5 \mathrm{~kg} \mathrm{~m}^{-3} \mathrm{~km}^{-1}$ and the relative displacement $\Delta X=7 \mathrm{~km}$, we have that $\Delta \rho \sim$ $1.75 \mathrm{~kg} \mathrm{~m}^{-3}$ which is of the right order, though somewhat less than the observed value on day 254 . This may be due to our underestimating the effective straining since the upper ADCP bin is $4 \mathrm{~m}$ below the surface, while the surface density is measured at $1 \mathrm{~m}$ depth and previous measurements of surface currents indicate the presence of significant nearsurface shear. As well as increasing the amplitude of the tidal straining, the missing component of near-surface shear may also be responsible for the apparent phase lag between the stratification and the straining, although mixing effects may be involved in delaying the time of maximum stratification.

\section{Process Synthesis in a Point Model}

In order to combine all these mechanisms and test the above conceptual mechanism for the generation of the semidiurnal oscillations in stability, we have utilized the one-dimensional (1-D) turbulence closure model of Simpson and Sharples [1992] to achieve a synthesis of the various processes operating in the ROFI regime. The model uses an explicit scheme to integrate the equations of motion:

$$
\begin{aligned}
& \frac{\partial u}{\partial t}=-\frac{1}{\rho} \frac{\partial P}{\partial x}+f v+\frac{\partial}{\partial z}\left(N_{z} \frac{\partial u}{\partial z}\right) \\
& \frac{\partial v}{\partial t}=-\frac{1}{\rho} \frac{\partial P}{\partial y}-f u+\frac{\partial}{\partial z}\left(N_{z} \frac{\partial v}{\partial z}\right)
\end{aligned}
$$

with $x$ and $y$ positive in the east and north directions, respectively, and $z$ increasing positively from the seabed. The second term on the right is the usual Coriolis forcing, and the third term is the effect of friction between the layers in transporting momentum vertically through the water column, with $N_{z}$ the coefficient of vertical eddy viscosity. Boundary conditions for the momentum equations are a quadratic stress law at the bottom and wind stress at the sea surface, using the hourly wind speed and direction observations.

The horizontal pressure gradient terms in (2) and (3) are approximated in the form

$$
\frac{1}{\rho} \frac{\partial P}{\partial x}=g\left(\frac{\partial \eta}{\partial x}\right)_{\text {tidal }}+g \frac{\partial \bar{\eta}}{\partial x}+g(h-z)\left(\frac{\partial \rho}{\partial x}\right)_{h}
$$

and similarly for the $y$ component. The first term on the right of (4) is a tidally oscillating sea surface slope, the second two terms represent the effect of a depth-invariant horizontal density gradient in setting up a mean surface slope and driving a depth-dependent density circulation. The components of the horizontal density gradient are determined from observations of temperature and salinity. Calculation of the mean surface slope is achieved by specifying a zero net flow condition in the cross-shore direction.

Horizontal advection and vertical diffusion of salinity and temperature at each level are controlled by

$$
\frac{\partial(s, T)}{\partial t}=-u \frac{\partial(s, T)}{\partial x}+\frac{\partial}{\partial z}\left[K_{z} \frac{\partial(s, T)}{\partial z}\right]
$$

where $\partial(s, T) / \partial x$ are the horizontal salinity and temperature gradients, again assumed depth independent and taken from observations. $K_{z}$ is the coefficient of vertical eddy diffusivity. There is no flux of salt or heat through the seabed and no net flux of salt at the surface. Surface heating is specified in 

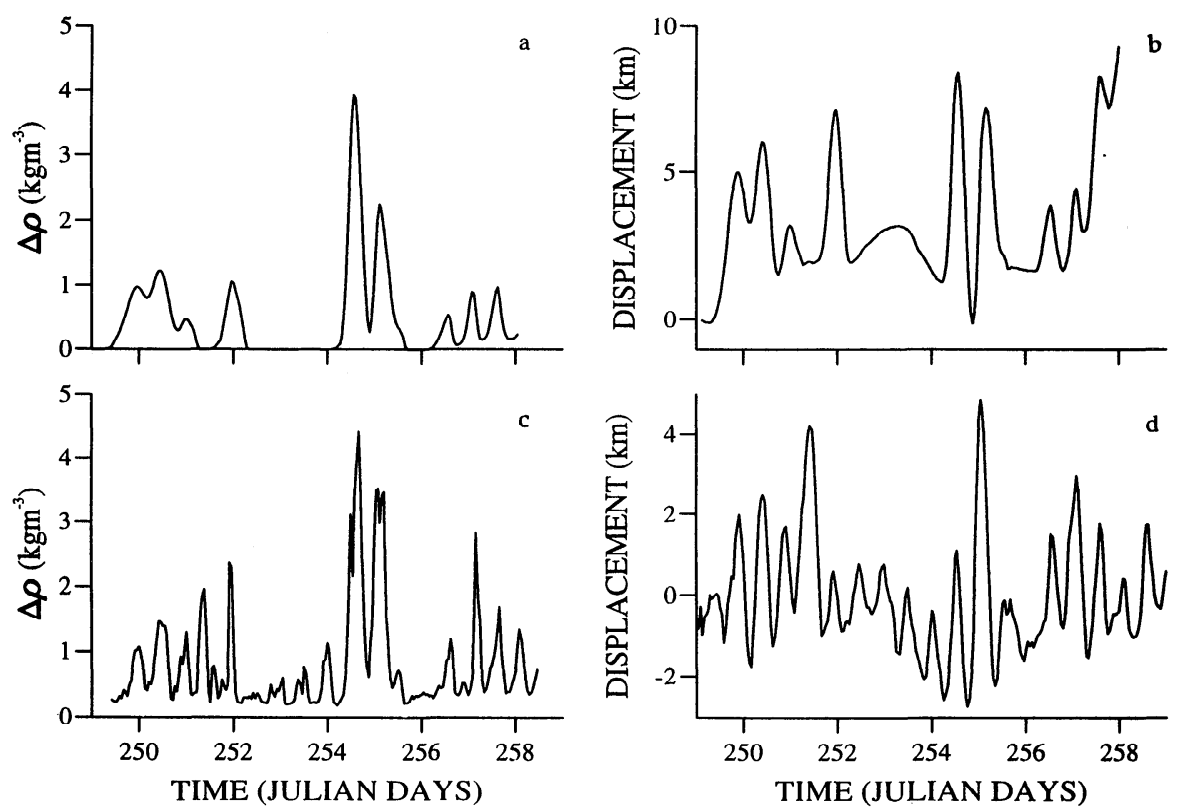

Figure 7. Stratification and displacement from the one-dimensional turbulence closure model: density stratification from (a) the model and (c) observations and relative displacement from (b) the model and (d) observations.

terms of the observed values of solar radiation, air temperature, relative humidity, and wind speed, following Gill [1982, p. 34]. Density $\rho$ is derived from temperature and salinity using the standard equation of state [UNESCO, 1981]. A level 2 turbulence closure scheme is used to calculate vertical profiles of $N_{z}$ and $K_{z}$ as functions of local stability [Mellor and Yamada, 1974] via

$$
\begin{gathered}
N_{z}=S_{M} l q ; \\
K_{z}=S_{H} l q
\end{gathered}
$$

where $q^{2}$ is the turbulent kinetic energy, $l$ is a mixing length, and $S_{M}$ and $S_{I I}$ are stability functions which depend on the local gradient Richardson number (for details, see Sharples and Simpson [1995]).

We have run this model with simplified forcing by surface slopes obtained from tide gauge observations at the mooring positions; the (predominant) cross-shore gradient derived from temperature and salinity measurements at moorings $\mathrm{A}$ and $\mathrm{D}$; and meteorological data provided by Koningklijk Nederlands Meteorologisch Institute, from the Noordwijk tower (wind speed, air temperature, and humidity), and Valkenberg (solar radiation).

Figure 7 shows the time series of stratification for the observations and the model. There is a good degree of correspondence between the two, with the model exhibiting the main features of the observations, notably the two strong maxima in $\Delta \rho$ on days $254-255$ which are simulated with satisfactory timing and magnitude. The preceding and following periods of near-zero stability are also reproduced by the model.

The model confirms the operation of the cross-shore straining mechanism in driving the semidiurnal oscillations of stability. In Figures $7 c$ and $7 d$ we see that the differential displacement between surface and bottom predicted by the model are of comparable magnitude and similar phasing to those observed. The suppression of tidal straining by enhanced vertical mixing is clearly apparent, if somewhat exaggerated, in the model results.

\section{Origin of the Cross-Shore Tidal Shear}

A striking feature of both observations and model results is the relatively large cross-shore straining which evidently operates during periods of stratification and which provides the primary drive for the semidiurnal oscillation. This straining, with a relative displacement of surface and bottom waters of $\sim 7 \mathrm{~km}$, is large in relation to the average amplitude of the cross-shore tidal flow. It appears to be associated with the change in the shape of the tidal ellipse which is brought about by the development of mean stratification, as reported on the basis of the 1990 observations by Visser et al. [1995]. Whereas at times of complete vertical mixing, the tidal ellipses are close to being degenerate (i.e., near-rectilinear motion), when the system stratifies, the surface ellipses exhibit pronounced clockwise motion, while the near-bed flow bccomes more anticlockwise in character.

This difference in behavior is due to the fact that in midlatitudes of the northern hemisphere the thickness of the bottom boundary layer $\delta_{-}$for clockwise motion is much greater than $\delta_{+}$for the anticlockwise component of motion. In depths of $-20 \mathrm{~m}$ the clockwise boundary layer extends to the surface, while anticlockwise motion at the surface is almost unaffected by bottom stress. With the onset of stratification the eddy viscosity is reduced and the consequent reduction in $\delta_{-}$means that the amplitude of surface clockwise currents increases, while that of the anticlockwise motion remains little changed. The result is an increase in clockwise rotation at the surface, while in the near-bed layers, where the frictional effects are now more concentrated, the clockwise component is reduced so the ellipses become more anticlockwise in character. The combined 
effect of these two changes is a marked increase in the cross-shore shear in the flow which produces the large relative displacements observed.

It should be noted that the phase of the tidal straining in relation to the elevation is quite different in this case from that observed in Liverpool Bay [Simpson et al., 1991], where the tidal motion is almost a pure standing wave and minimum stratification tends to occur close to high water (HW). In the present case (Figure 8) the tide is better described by a Kelvin wave traveling to the northeast along the Dutch coast and the maximum alongshore current occurs near local HW. The phase of the cross-shore shear during times of stratifcation is such that minimum stability occurs near low water.

\section{Summary and Discussion}

The presence of semidiurnal oscillations in stability appears to be a general characteristic of the Rhine ROFI under conditions of weak mixing. The present data, the 1990 observations [Bos et al., 1990; Simpson et al., 1993], and previous time series observations [van Alphen et al., 1988] all indicate large semidiurnal cycles whenever the system exhibits strong mean stratification. The two phenomena, i.e., semidiurnal periodic and mean stratification, would thus seem to be inextricably linked. On the basis of the above results and analysis we hypothesize that the mechanism responsible involves the sequence of interactions illustrated in Figure 9.
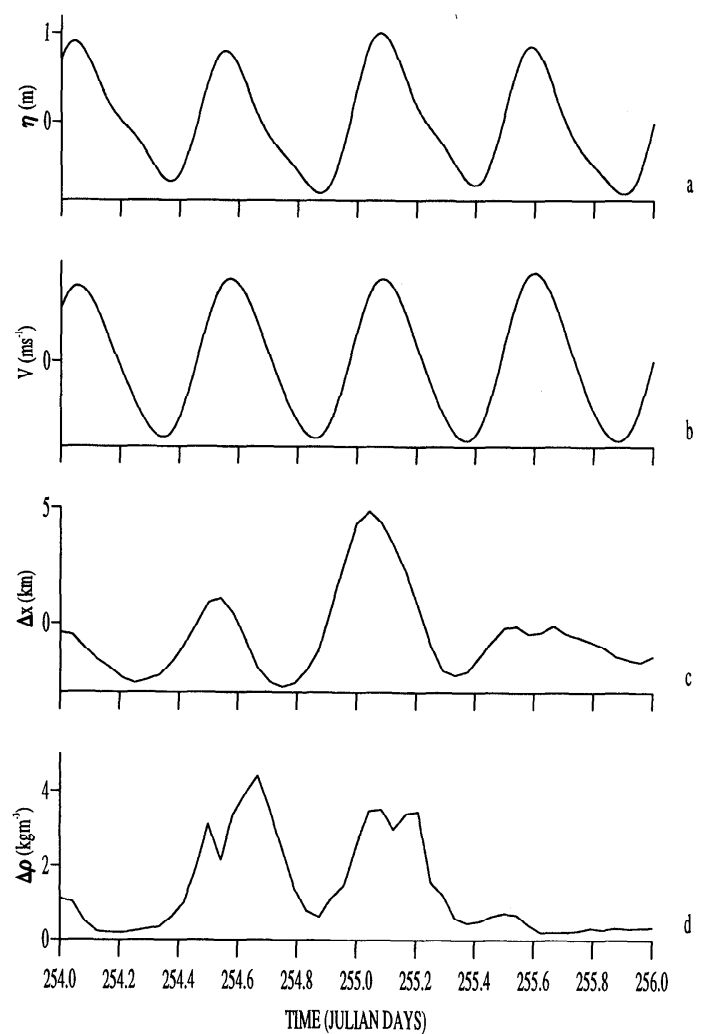

Figure 8. The relation between straining and the propagation of the tidal wave from measurements at mooring A showing (a) tidal elevation, (b) alongshore velocity, (c) relative displacement between 4 and $16 \mathrm{~m}$, and (d) density difference.

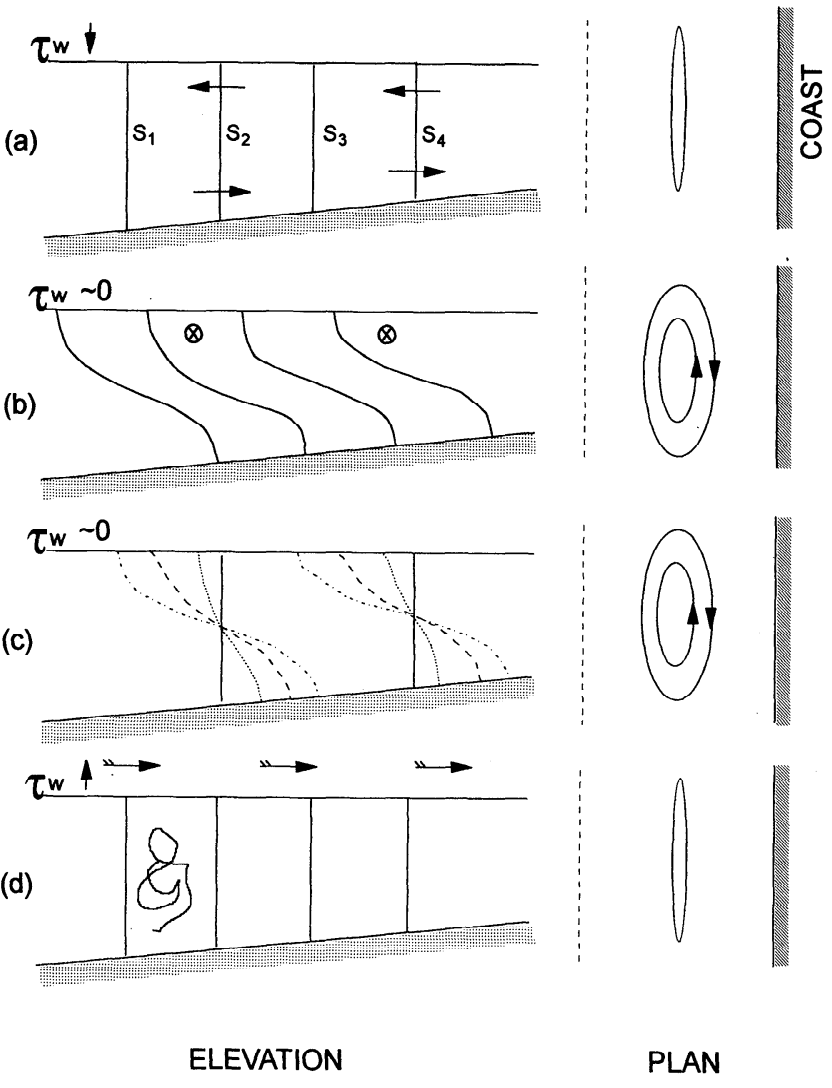

Figure 9. (a)-(d) Process summary schematic showing the changes in ellipse format at surface and bottom due to the onset of stratification and the resulting semidiurnal oscillations in stability driven by tidal straining. See text for details.

Following a period of complete vertical mixing, when all the isolines are vertical (Figure 9a), the density gradients start to relax under gravity, as in the Linden and Simpson [1988] experiments. This spreading would, in the absence of tidal processes, result in a steady state coast parallel flow (Figure $9 \mathrm{~b}$ ) under the influence of rotation, as in the model of $O u$ [1983]. The stratification induced then causes a change in the tidal ellipses by decoupling the surface and bottom layers (Figure 9c). The resulting offshore tidal straining initiates oscillations in stability which combine with the mean stratification to give the observed pattern of stability variation, with the system coming close to or reaching complete vertical mixing in each tidal cycle. When wind and/or tidal stirring increase again (Figure 9d), vertical exchange is enhanced and the tidal shear is suppressed as the ellipses revert to near-degenerate form and the density stratification is broken down.

In this picture it is the tidal straining due to changes in the form of the tidal ellipse which is the essential process coupling the mean and oscillating components of the stratification. Such changes in eccentricity with the stability of the water column have been documented in a number of other situations in thermally stratified waters [Maas and van Haren, 1987; Lwiza et al., 1991], and we might expect analogous effects to occur in other ROFIs. The extent to which this will induce semidiurnal oscillations in stability will depend on the orientation of the induced shear in relation to the horizontal density gradients. 
A striking feature of the Rhine ROFI is that it is the interaction of the minor axis component of the tidal ellipse with the density gradient which induces the large straining signal. This contrasts with the situation in Liverpool Bay [Sharples and Simpson, 1995], where the straining is due to the major axis component of the almost degenerate tidal ellipse, which is almost parallel to the density gradient vector. Changes in ellipse properties with stratification do occur here and induce additional shear along the minor axis direction. There is, however, little enhancement of the semidiurnal stratification because the minor axis shear component is almost orthogonal to the density gradient vector.

Recognition of the strong influence of large semidiurnal variability in the Rhine ROFI due to tidal straining might usefully lead to a reinterpretation of previous data sets from the region. Investigators, ourselves included, have frequently attempted to interpret survey data in terms of quasi-stationary spatial distributions which, in the presence of the considerable short-term variability, will include spurious spatial structure.

The qualitative success of the model in predicting the onset of mean stratification and hence semidiurnal oscillations is, perhaps, surprising, in that our 1-D representation does not include the influence of the coastline which, as we noted above, would be expected to cause marked directional effects in the action of wind stress. Regressions of the daily mean $\Delta \rho$ on the alongshore and cross-shore components of wind stress and significant wave height (measured at the Noordwijk tower) demonstrate strong partial correlations with all three variables and explain $69 \%$ of the variance in the 12-day observational period reported here. The implication would seem to be that we might expect significant improvement in model performance from a two-dimensional slice model which includes the influence of the coast and from the explicit inclusion of wave stirring, based on an appropriate parameterization using observed wave height data.

Another alternative mechanism, suggested by a referee, which the model presently neglects and which may contribute to the development of cross-shore shear, is the advection of a horizontally varying, geostrophic flow field by the tidal currents. Further modeling experiments are required to determine the contribution of this form of interaction and the way it depends on changes in stratification, but, at this stage, we would argue that the satisfactory prediction of the cross-shore displacement and ellipse adjustment by the 1-D model indicate that this form of interaction is not important in the interior region of the ROFI, where we have concentrated our modeling simulations.

Acknowledgments. This work was conducted within PROFILE, a European funded project under the MAST programme, contract EC(MAST)-CT93-0054. A. J. Souza wishes to thank CONACYT, Mexico, for support through a studentship. We are pleased to acknowledge helpful comments and valuable suggestions during the review procedure from Rich Garvine.

\section{References}

Bos, W. G., A. W. Visser, C. Heins, G. J. Kolle, and P. C. Benkenkamp, Integrated modelling and measurement of physical controlled fluxes and plankton dynamics in coastal sea, data report, Holland Surveys, Rijkswaterstaat, October 1990.
Bowden, K. F., and S. H. Sharif el Din, Circulation and mixing processes in the Liverpool Bay area of the Irish Sea, Geophys. J. R. Astron. Soc., 11, 279-292, 1966.

de Ruijter, W. P. M., A. van der Giessen, and F. C. Groenendijk, Current and density structure in the Netherlands coastal zone, in Dynamics and Exchanges in Estuaries and the Coastal Zone, Coastal Estuarine Stud. Ser., vol. 40, edited by D. Prandle, pp. 529-550, AGU, Washington, D. C., 1992.

Gill, $\Lambda$. E., Atmosphere-Ocean Dynamics, 662 pp. Academic, San Diego, Calif., 1982.

Linden, P. F., and J. E. Simpson, Modulated mixing and frontogenesis in shallow seas and estuaries, Cont. Shelf. Res., 8, 1107$1127,1988$.

Lwiza, K. M. M., D. G. Bowers, and J. H. Simpson, Residual and tidal flow at a tidal mixing front in the North Sea, Cont. Shelf. Res., 11, 1379-1991, 1991.

Maas, L. R. M., and J. J. M. van Haren, Observations of the vertical structure of tidal and inertial currents in the central North Sea, $J$. Mar. Res., 45, 293-318, 1987.

Mellor, G. L., and T. Yamada, A hiearchy of turbulence closure models for planetary boundary layers, J. Atmos. Sci., 31, 17911806, 1974.

Munchow, A., and R. W. Garvine, Dynamical properties of buoyancy driven coastal current, J. Geophys. Res., 98(C11), 20,06320,077, 1993.

$\mathrm{Ou}, \mathrm{H}$. W., Some two-layer models of shelf-slope front: Geostrophic adjustment and maintenance, J. Phys. Oceanogr., 13, 1798-1808, 1983.

Sharples, J., and J. H. Simpson, Semi-diurnal and longer period stability cycles in the Liverpool Bay R.O.F.I., Cont. Shelf Res., $15,295-313,1995$.

Simpson, J. H., and D. G. Bowers, Models of stratification and frontal movements in the shelf seas, Deep Sea Res., Part A, 28A, 727-738, 1981.

Simpson, J. H., and J. Sharples, Dynamically-active models in prediction of estuarine stratification, in Dynamics and Exchanges in Estuaries and the Coastal Zone, Coastal Estuarine Stud. Ser., vol. 40, edited by D. Prandle, pp. 101-113, AGU, Washington, D. C., 1992.

Simpson, J. H., J. Brown, J. Matthews, and G. Allen, Tidal straining, density currents and stirring control of estuarine stratification, Estuaries, 13(2), 125-132, 1990.

Simpson, J. H., J. Sharples, and T. P. Rippeth, A prescriptive model of stratification induced by freshwater run-off, Estuarine Coastal Shelf Sci., 33, 23-35, 1991.

Simpson, J. H., W. G. Bos, F. Schirmer, A. J. Souza, T. P. Rippeth, S. E. Jones, and D. Hydes, Periodic stratification in the Rhine ROFI in the North Sea, Oceanol. Acta, 16(1), 23-32, 1993.

Uncles, R. J., W. K. Gong, and J. E. Ong, Intratidal fluctuations in stratification within a mangrove estuary, Hydrobiologia, 247, 163-171, 1992.

UNESCO, Tenth Report of the Joint Panel on Oceanographic Tables and Standards, UNESCO Tech. Pap. Mar. Sci., 36, 24 pp., 1981.

van Alphen, J. S. L. J., W. P. M. de Ruijter, and J. C. Borst, Outflow and three-dimensional spreading of Rhine River water in the Netherlands Coastal zone, in Physical processes in Estuaries, edited by J. Dronkers and W. Van Leussen, pp. 70-92. SpringerVerlag, New York, 1988.

van der Giessen, A., W. P. M. de Ruijter, and J. C. Borst, Three-dimensional current structure in the Dutch coastal zone, Neth. J. Sea Res., 25(1/2), 45-55, 1990.

Visser, A. W., A. J. Souza, K. Hesser, and J. H. Simpson, The influence of water column stratification on tidal current profile in a ROFI system, Oceanol. Acta, in press, 1995.

J. H. Simpson and A. J. Souza, School of Ocean Sciences, University College North Wales, Menai Bridge, Gwynedd LL59 5EY, Wales. (e-mail: OSS035@SOS.baugor.ac.uk;osp126@SOS. baugor.ac.uk)

(Received April 27, 1994; revised November 14, 1994; accepted November 18, 1994.) 